\title{
Professor: Um profissional em construção permanente ${ }^{1}$
}

\author{
Inés Kayon de Miller \\ PUC-Rio \\ Isabel Cristina Rangel Moraes Bezerra \\ FFP/UERJ e IECP
}

\begin{abstract}
Resumo: Este trabalho tem por objetivo discutir a formação docente como um processo de construção permanente, focalizando a construção de conhecimentos lingüísticos bem como a construção de uma atitude reflexiva através do olhar investigativo à sala de aula. Para tal, pretende-se apresentar a Prática Exploratória - uma forma de ensinar e aprender que encoraja os participantes de sala de aula a olhá-la como uma fonte inesgotável de puzzles ou questões a serem investigadas. Discutiremos os princípios deste paradigma de pesquisa do praticante e ilustraremos um processo de ação investigativa, que está gerando entendimentos sobre a vida no contexto estudado.
\end{abstract}

Palavras-chave: formação docente, natureza da linguagem; atitude reflexiva; Prática Exploratória; ensino de línguas.

\section{INTRODUÇÃO}

A formação docente é por nós entendida como um processo permanente. No que se refere à formação do professor de línguas, deve, por um lado, focalizar a construção de conhecimentos teóricos sobre linguagem, aprendizagem e metodologia específica para o ensino de línguas; por outro, deve proporcionar a construção de uma atitude reflexiva através do olhar investigativo à sala de aula. No que diz respeito à primeira questão, discutiremos como perspectivas de linguagem e de aprendizagem definem escolhas metodológicas, estando presentes desde a formação inicial do professor. Para a segunda questão, pretendemos apresentar a Prática Exploratória - uma forma de ensinar e aprender que encoraja os participantes da sala de aula a olhá-la como fonte inesgotável de puzzles ou questões a serem investigadas.

\section{FORMAÇÃO DOCENTE, FORMAÇÃO PERMANENTE}

\footnotetext{
${ }^{1}$ Esse artigo é um desenvolvimento das idéias discutidas na mesa redonda com o mesmo título por nós apresentada, em 2004, durante o I Encontro do Fórum Permanente de Estudos de Língua e Literatura, na FFP/UERJ.
} 
Pensamos que tornar-se professor é um processo que se inicia, de alguma forma, assim que entramos na escola, continua na escola normal ou na licenciatura e deve ser uma história sem fim. No que diz respeito ao profissional de Letras e, mais especificamente o professor de inglês, há algumas questões cruciais que deveriam ser a preocupação dos professores que participam desse processo de inserção de um novo membro na comunidade docente. A primeira delas diz respeito à questão lingüística. Isso significa falar sobre a influência da visão de linguagem que permeia o discurso e a prática dos professores formadores na compreensão que o futuro professor terá da língua que ensina. Em outras palavras, os professores formadores, conforme aponta Moraes Bezerra (2000), podem entender a língua a partir de uma das seguintes perspectivas:

[a] estrutural - o futuro professor pode entender que saber uma dada língua significa dominar-lhe as estruturas sintáticas/regras gramaticais. O foco do ensino recai sobre os elementos sistêmicos da língua e a sentença é a unidade de ensino. Tal entendimento é decorrente de estudos lingüísticos, como os de Chomsky $(1957,1965)$ com o construto competência lingüística, que focalizavam a linguagem enquanto regras a serem aprendidas;

[b] comunicativa - o futuro professor pode entender que saber uma dada língua significa utilizá-la para a comunicação. Assim, o discurso deve ser apropriado ao contexto social de uso, considerando seus participantes e, além disso, ser coeso e coerente. O foco do ensino recai sobre o discurso, de sorte que o texto - oral ou escrito - deve tornar-se a unidade de ensino. Tal perspectiva, por sua vez, surgiu da contribuição de Hymes (1972), ao refutar a tese de que apenas o foco na competência lingüística daria conta de entender o uso que o falante faz de uma dada língua. Ele propõe o construto competência comunicativa, da qual a competência lingüística seria apenas um dos componentes;

[c] sociointeracional - o futuro professor pode entender que saber uma dada língua significa ser capaz de engajar-se discursivamente no processo de negociação de significados. Neste, estão também envolvidos a negociação de poder, bem como o componente ideológico do qual a língua está plena. Assim, ao utilizar uma dada língua, o falante o faz enquanto uma ferramenta para a ação social. Dessa forma, a construção dialógica de significados dá-se contextualizadamente no espaço social e na história, através das escolhas lingüísticas feitas pelos interactantes. Tais escolhas mostram como os interactantes posicionam-se e ao outro no discurso, construindo as relações e o mundo social. Tal entendimento teve sua gênese em estudos de Bakhtin ([1929] 2002), Foucault ([1971] 2002a, [1979] 2002b), Fairclough (1992, 1996), inter alia, e servem de base para a teoria sobre linguagem que fundamenta os Parâmetros Curriculares Nacionais - Língua Estrangeira (1998) para o ensino fundamental. 
As dimensões trazidas por cada uma dessas perspectivas vão orientar de forma bastante diversa a prática do professor de inglês. Sem deixar em segundo plano o ensino dos elementos sistêmicos da língua, adotamos a terceira visão de linguagem como a mais pertinente para a formação daquele profissional. Entendemos que só ela é capaz de colaborar para a formação do sujeito crítico.

Outra questão relevante para a formação do professor de inglês diz respeito aos aspectos teórico-metodológicos. Mantendo relação direta com a visão de língua adotada, tais aspectos envolvem também um entendimento acerca do processo ensino-aprendizagem. Assim, considerando a visão por nós privilegiada, que focaliza os significados construídos com o outro através do discurso, acreditamos que, sem excluir do currículo do profissional em formação conteúdos referentes às mais diversas teorias psicológicas sobre o fenômeno da aprendizagem, seria necessário adotar uma teoria que com ela dialogasse. Por isso, adotamos princípios oriundos da teoria sócio-histórica de Vygotsky (1998), acrescidos da contribuição dos neo-vygotskyanos (Cazden, 1988, Bruner, 1986, Edwards e Mercer, 1987, inter alia) como base para a compreensão do processo de aprender em que um par mais competente, ao utilizar a linguagem para agir na zona de desenvolvimento proximal, constrói conhecimentos com o aprendiz em relação a uma tarefa que o segundo não consegue fazer de forma autônoma. Essa intervenção fará com que o seu desenvolvimento potencial torne-se real. Por outro lado, todo esse processo será marcado pelo social, pela história trazida por todos para o evento e cujas marcas estão presentes no discurso.

Em termos metodológicos, significa perceber a importância das tarefas propostas aos aprendizes, uma vez que será preciso, via de regra, partir do já construído para atingir outros níveis de compreensão. Além disso, significa propiciar oportunidades para que os aprendizes interajam não apenas com o professor, mas com outros aprendizes através da linguagem ferramenta simbólica fundamental ao processo. Sendo assim, se tomarmos os drills, tão comuns em algumas propostas para o ensino de idiomas, poderíamos transformá-los em atividades na quais os aprendizes tivessem de refletir e discutir entre si para elaborar as transformações nas estruturas sintáticas, ao invés de trazê-los para a sala de aula como mera atividade de memorização. Como um passo adiante, os aprendizes tentariam observar como os elementos lingüísticos contribuem para a construção de significado, muitas vezes apontando para nuances em termos de posicionamento dos interlocutores no discurso. Além disso, observar possíveis nuances na estruturação do mesmo, promovidas pelas escolhas gramaticais, uma vez que essas são determinadas pelo contexto de uso (quem são os participantes e qual a relação entre eles, o tópico, o que se pode ou não dizer, etc.). 
Sublinhamos que essa é apenas uma proposta para a formação inicial que deve estender-se por toda a carreira do professor de inglês, pois, conforme lembra Fullan (1991:289), “a educação do professor, ou o professor enquanto aprendiz, deve ser entendida, desde o primeiro dia, como uma proposta para toda a sua carreira. A educação do professor ou o desenvolvimento do professor é um contínuo de aprendizagem”. Em outras palavras, a educação do professor de inglês, nosso foco de interesse, acontece dentro e fora da sala de aula, durante seu pré-serviço, bem como a partir do momento em que se torna um profissional com a chancela de uma instituição de ensino superior. Ele seguirá construindo saberes na prática cotidiana com seus alunos, bem como em outros eventos e em espaços institucionais pelos quais circular - incluímos conversas com seus colegas na sala dos professores, reuniões pedagógicas, outros cursos, congressos, etc.

Permeando essa formação, há um outro elemento a ser co-construído com os professores formadores: uma atitude reflexiva sobre a própria prática docente. Ela é crucial para que o professor não se entenda como mero consumidor de teorias (Moita Lopes, 1996), como se ele não tivesse coisa alguma a dizer sobre seu fazer ou sobre como seus alunos aprendem. Assim, na próxima seção, apresentamos a Prática Exploratória como uma possibilidade de fundamentar aquela atitude.

\section{A PRÁTICA EXPLORATÓRIA: BUSCANDO ENTENDER A VIDA EM SALA DE AULA}

A Prática Exploratória ${ }^{2}$ é uma forma de ensinar e aprender que integra um olhar curioso e investigativo ao trabalho pedagógico. É uma proposta que oferece a professores e alunos oportunidades de transformarem-se em agentes da construção de entendimentos sobre a vida na sala de aula, enquanto trabalham no processo de ensinar e aprender, conforme sinaliza Allwright (2002). O trabalho para entender se organiza em Atividades Pedagógicas com Potencial Exploratório (APPEs) que, dentro de uma visão ampla, podem incluir atividades familiares como monitoração, realização de exercícios, discussão em grupos, etc. Essa forma de olhar a sala de aula, pelo envolvimento que provoca entre os praticantes, dialoga não apenas com a visão de linguagem, mas também com a de aprendizagem por nós adotada, uma vez que insere os participantes discursivos no social e na história. Devido à integração dos questionamentos com a prática pedagógica cotidiana, a PE vai além de proporse enquanto metodologia de pesquisa.

\footnotetext{
2 'PE' de agora em diante.
} 
Segundo Allwright (2003:124-125), há alguns macro e micro processos centrais na PE. Assim, os praticantes envolvidos buscam agir para entender, ao:

- trazerem questões da vida de sala de aula para a consciência;

- refletirem mais intensamente com colegas e/ou co-participantes dentro e fora de sala de aula;

- olharem, ouvirem, sentirem - ficarem mais atentos ao que acontece em sala de aula, enquanto está acontecendo;

- planejarem para entender através de atividades pedagógicas.

Podemos dizer que os participantes também trabalham com os entendimentos resultantes ao:

- expressarem e avaliarem entendimentos pessoais e/ou coletivos de forma reflexiva;

- refinarem noções comuns de 'mudança' como sinônimo de 'melhora';

- discutirem decisões pessoais ou coletivas; e

- compartilharem processos de entendimento pessoal de modo a 'apoiarem' outros e a agregarem outros na comunidade de prática da PE.

Esses processos, que caracterizam o 'fazer' da PE, vêm sendo articulados e reelaborados por Allwright (2003), Miller e Moraes Bezerra (2004) e outros praticantes exploratórios (Lyra et al, 2003; Kuschnir \& Machado, 2003; Miller, 2003; Slimani-Rolls, 2003; Perpignan, 2003; Moraes Bezerra, 2003a e 2003b; inter alia) como um conjunto de princípios que norteiam a atitude reflexiva que se faz através da PE. São eles:

Colocar a qualidade de vida em primeiro lugar.

Trabalhar para entender a vida em sala de aula.

Envolver todos nesse trabalho.

Trabalhar para a união de todos.

Trabalhar também para o desenvolvimento mútuo.

A fim de evitar que o trabalho para o entendimento esgote seus participantes, integrar este trabalho com as práticas da sala de aula.

Fazer com que o trabalho seja contínuo e não uma atividade dentro de um projeto.

Fulcrada nas inter-relações entre os interactantes e nas ações pedagógicas desenvolvidas por todos para ensinar e aprender, a reflexão é gerada a partir de puzzles ou questões a serem entendidas. Os puzzles podem ser propostos não apenas pela professora, mas também pelos alunos, colaborando para que todas as vozes possam manifestar-se no espaço discursivo tanto no embate quanto no consenso, mas sempre objetivando a construção de uma atitude ética de respeito pelo outro. 
Apresentamos aqui, a título de ilustração, algumas questões que alunos e professores exploraram ao agir para entender suas vidas na sala de aula de língua inglesa e cujos entendimentos resultantes eles apresentaram em eventos da Prática Exploratória, organizados entre 1999 e 2004 (maiores informações, podem ser obtidas no site http://www.letras.pucrio.br/epcentre/).

Os exemplos selecionados mostram duas professoras e três alunas que, apesar de atuarem em contextos diferentes, preocupam-se com questões referentes ao processo ensinoaprendizagem que se dá na sala de aula, fora dela e às relações co-construídas entre professor e alunos. As breves narrativas que acompanham cada questão descrevem como os praticantes envolvidos trabalharam juntos para gerar entendimentos, integrando os membros dos grupos e suas práticas de ensino-aprendizagem.

Questão: Por que minha responsabilidade aumenta enquanto a dos meus alunos diminui?

A professora havia pedido que seus alunos de magistério (E.M.) lessem alguns livros. Ela própria leu todos os livros e preparou atividades variadas para cada livro. O resultado dos trabalhos não foi satisfatório. Para procurar entender sua questão, a professora preparou uma APPE: um texto sobre uma professora que trabalhava muito, mas que não tinha alunos que correspondessem. Depois de lerem o texto e fazerem o trabalho de compreensão e vocabulário, houve uma discussão sobre os assuntos do texto: responsabilidade, trabalho, papel do professor, etc. A professora entendeu que os alunos deixavam de fazer as tarefas por diversas razões, mas não por falta de interesse. Por outro lado, os alunos passaram a dar mais valor a sua produção, enquanto alunos, e ao trabalho da professora. Ela enfatizou que, pelo fato de haver trabalhado a questão como algo hipotético, houve maior facilidade para os alunos engajarem-se na discussão sobre responsabilidade e dedicação, até chegarem a dimensioná-la no nível pessoal. (Prof. S.F., 2002)

Questão: Por que a gente não entende a professora de inglês?

As alunas pediram permissão para a professora de inglês para gravar a aula. Depois, tentaram ouvir a gravação e transcrever trechos. Mais tarde, mostraram o material coletado para esta professora. Depois da análise do material, fizeram comentários sobre o comportamento dos alunos e o uso do inglês em sala pela professora. (Duas alunas da $6^{\mathrm{a}}$. série, C.d.Q., 2002)

Questão: Por que meus alunos dizem que não aprenderam nada se eles estão estudando inglês há um ano?

A professora colocou uma folha de papel pardo no quadro com o título: Aprendizagem. Ela perguntou aos alunos o que eles pensavam sobre este tópico, onde eles aprendiam inglês e quais palavras eles associavam com o título. Enquanto eles respondiam, ela escrevia no papel. Ao final, houve uma discussão sobre o assunto. Em outra ocasião, ela trouxe perguntas sobre o professor ideal e sobre como poderiam melhorar seu aprendizado da língua inglesa. Essa atividade pedagógica proporcionou à professora e aos alunos maior entendimento sobre as crenças do grupo a respeito do 
processo de ensino-aprendizagem em geral e a influencia do envolvimento pessoal nesse processo. Em outra palavras, refletiram sobre de quem é a responsabilidade para aprender: apenas da professora que satisfaz os desejos dos alunos e fica revisando e propondo atividades e/ou também dos alunos que podem assumir sua parcela de responsabilidade pela construção do próprio conhecimento? (Prof. L.S., P. 2003)

Questão: A minha maneira de estudar inglês é boa?

Questionando sua forma aparentemente desorganizada de estudar, a aluna preparou uma lista de coisas que fazia antes e durante seu momento de estudo em casa. Também entrevistou seus familiares e os seus colegas considerados bons alunos, sobre seus métodos de estudo. Depois, ao comparar todas essas práticas, ela entendeu que seus métodos de estudo eram tão válidos quantos os dos seus familiares e colegas. (Aluna B., 6a. série, CAp-UFRJ, 1999)

No fazer da PE, reconhecemos a 'vida' escolar como parte integrante da 'vida' dos professores e alunos e a 'qualidade de vida' em sala de aula como prioridade. À luz de uma perspectiva Bakhtiniana, percebemos o cotidiano escolar na PE como um espaço onde se incentiva a enunciação das múltiplas vozes que participam da vida em sala de aula, i.e., um espaço que privilegia a polifonia. Na busca de entendimentos de questões relativas à vida dentro e fora de sala de aula, encontramos os participantes profundamente engajados no processo dialógico com o outro, dentro da cadeia sócio-histórica. Percebemos que eles agem como sujeitos agentes que constroem, dentro de suas vidas institucionais, tempo e espaço para buscar entendimentos sobre suas questões. Na PE intensifica-se a integração social dos coparticipantes entre si, com a prática pedagógica local e com o ensino-aprendizagem enquanto processo social contínuo.

Ao manter-se o foco no entendimento do que acontece em sala e fora dela e na integração entre as pessoas, o trabalho realizado para entender faz com que professores e alunos exploratórios deixem de ser 'seguidores’ de métodos ou consumidores de teorias. Eles passam a re-significar as práticas pedagógicas como construções sócio-históricas ao entendêlas como práticas com potencial investigativo e reflexivo. Praticantes exploratórios geram, assim, transformações discursivas em contextos pedagógicos e se constroem como permanentes aprendizes.

\section{Referências bibliográficas}

Allwright, D. (2003). Exploratory Practice: Rethinking practitioner research in language teaching. In Ellis, Rod (ed.) Language Teaching Research. London: Arnold, 7 (2), 113-141.

Bruner, J. (1986). Actual minds, possible words. Cambridge, Mass.: Harvard University Press. 
Cazden, C. (1988). Classroom discourse: The language of teaching and learning. Portsmouth, N. H.: Heinemann.

Chomsky, N. (1957). Syntactic structures. The Hague: Mouton.

(1965). Aspects of the theory of syntax. Cambridge, Mass.: MIT Press.

Edwards, D; Mercer, N. (1987). Common knowledge - The development of understanding in the classroom. London, New York: Routledge.

Fairclough, N. (1992). Discourse and social change. Cambridge: Polity Press.

(1996). Language and power. London: Longman.

Foucault, M. A ([1971] 2002a).Ordem do discurso. São Paulo: Edições Loyola.

([1979] 2002b). Microfísica do poder. Rio de Janeiro: Edições Graal.

Fullan, M. (1991). The new meaning of educational change. London: Cassell.

Hymes, D. (1972). On Communicative competence. In Pride, J. B. \& Holmes, J. (eds.) Sociolinguistics. Middlesex, N. York: Penguin Books, 269-293.

Kuschnir, A. \& B. Machado. (2003). Puzzling and puzzling about puzzle development. Language Teaching Research, 7 (2), 163-180.

Lyra, I. et al. (2003). What puzzles teachers in Rio de Janeiro, and what keeps them going? Language Teaching Research, 7 (2), 143-162.

Miller, I.K. (2003). Researching teacher-consultancy via Exploratory Practice. Language Teaching Research, 7 (2), 201-219.

Moraes Bezerra, I. C. R. (2003 a). Prática Exploratória: um caminho para o entendimento. Pesquisas em Discurso Pedagógico 2(2), 58-72.

(2003 b). Aprender e ensinar inglês: o que o afeto tem a ver com isso? Rio de Janeiro: Departamento de Letras/ PUC-Rio, mimeo.

Miller, I. K; Moraes Bezerra, I. C. R. (2004). Professor: um profissional em construção permanente. Mesa redonda, I Encontro do Fórum Permanente de Língua e Literatura Inglesa. Faculdade de Formação de Professores/UERJ, São Gonçalo, RJ.

Parâmetros Curriculares Nacionais: terceiro e quarto ciclos do ensino fundamental: língua estrangeira. (1998). Secretaria de Educação Fundamental. Brasília: MEC/SEF.

Perpignan, H. (2003). Exploring the written feedback dialogue: a research, learning and teaching practice. Language Teaching Research, 7 (2), 259-278.

Slimani-Rolls, A. (2003). Exploring a world of paradoxes: an investigation of group work. Language Teaching Research, 7 (2), 221-239.

Vygotsky, L. S. (1998). A Formação Social da Mente. São Paulo: Martins Fontes.

(1993). Pensamento e Linguagem. São Paulo: Martins Fontes.

\section{AS AUTORAS}

Inés Kayon de Miller é doutora em Lingüística Aplicada pela Universidade de Lancaster (Inglaterra) e atua no Departamento de Letras, PUC-Rio, na linha de pesquisa em Discurso, Interação e Cultura em Contextos Espontâneos, Profissionais e Pedagógicos. Co-coordena o trabalho do Grupo da Prática Exploratória do Rio de Janeiro, integrado por professores e alunos multiplicadores que refletem sobre suas vidas no cotidiano escolar. E-mail: inesmiller@hotmail.com 
Isabel C. R. Moraes Bezerra é doutora Letras (Estudos da Linguagem) pela PUC-Rio. Atua como professora assistente na Faculdade de Formação de Professores-UERJ. Seus interesses de pesquisa envolvem análise do discurso profissional, ensino/aprendizagem de língua inglesa, construção de conhecimento e de identidade docente, produção de material didático.

E-mail: icmoraes@uol.com.br 